\title{
A ORIENTAÇÃO FÍSICO-ESPACIAL DE PESSOAS COM DEFICIÊNCIA VISUAL: CONHECENDO O USUÁRIO
}

\author{
Mariana de Sousa Siqueira Santos ${ }^{1}$
}

\author{
Angelina Dias Leão Costa ${ }^{2}$
}

\begin{abstract}
RESUMO
A prática projetual desenvolvida na atualidade ainda parece apontar para uma mobilização exacerbada do sentido da visão, o que coloca as pessoas com deficiência visual em situações desvantajosas. Pode-se exemplificar tais desvantagens com a dificuldade de elaborar uma rota mental adequada que lhes permita autonomia e desenvoltura na interação com o ambiente construído, já que há poucos ou inexistentes marcos referenciais em um determinado espaço. Este artigo baseia-se na premissa de que conhecer as maneiras como se estruturam a percepção e orientação espacial de usuários com deficiência visual pode ajudar os projetistas, como também favorece o desenvolvimento de espaços que atendam às necessidades de orientação espacial desse grupo específico. Desse modo, o objetivo deste artigo é apresentar partes do aporte teórico da dissertação de mestrado em andamento, abordando conceitos como orientação espacial, legibilidade, wayfinding e multissensorialidade. Acredita-se que através do diálogo entre o usuário e o profissional, bem como dos subsídios teóricos e legais relacionados à temática, pode-se contribuir com a busca de soluções de problemas de orientação espacial que os usuários em questão enfrentam em ambientes construídos.
\end{abstract}

PALAVRAS-CHAVE: Deficiência visual. Orientação físico-espacial. Multissensorialidade.

\footnotetext{
${ }^{1}$ Mestranda do Programa de Pós-Graduação de Arquitetura e Urbanismo (PPGAU), Universidade Federal da Paraíba. E-mail: masiqueira86@gmail.com

${ }^{2}$ Professora Doutora, Universidade Federal da Paraíba. E-mail: angelinadlcosta@yahoo.com.br
} 


\title{
A PHYSICAL SPACE ORIENTATION OF PEOPLE WITH VISUAL IMPAIRMENT: GETTING TO KNOW YOU
}

\begin{abstract}
The design practice developed at present, still seems to point to a intensified mobilization of the sense of sight, which puts people with visual impairment in disadvantageous situations, often these situations constitute a difficulty of developing the adequate mental route, which they allow autonomy and ease in interaction with the spatial environment due to lacking or insufficient benchmarks in a given space. This article is based on the premise that to know the visually impaired helps those who seek to understand how they orient themselves spatially and how to develop spaces that meet the needs of users with visual impairment in their physical and spatial orientation. Therefore, the purpose of this article is to present some parts of the theoretical basis of the dissertation in progress, approaching concepts such as spatial orientation, legibility, wayfinding and multisensoriality. It is believed that through dialogue between the user and the professional as well as the theoretical and legal subsidies related to the subject can contribute to the search for solutions of spatial orientation problems of users in question face in built environments.
\end{abstract}

KEYWORDS: Visual impairment. Spatial orientation. Multisensoriality.

\section{UN ESPACIO DE ORIENTACIÓN FÍSICA DE LAS PERSONAS CON DISCAPACIDAD VISUAL: CONOCER EL USUARIO}

\section{RESUMEN}

La práctica de diseño desarrollada en la actualidad, todavía parece apuntar a una movilización intensificada del sentido de la vista, que pone a las personas con discapacidad visual en situaciones desventajosas, a menudo estas situaciones se resumen a una dificultad de desarrollo de la ruta mental adecuada, que permiten autonomía y facilidad en la interacción con el ambiente construido debido a la falta o insuficiente de referencia en un espacio. Este artículo se basa en la premisa de que conocer los discapacitados visuales ayuda a aquellos que buscan comprender cómo ellos se orientan espacialmente y desarrollar espacios que satisfagan las necesidades de los usuarios con discapacidad visual en su orientación espacial y físico. Por lo tanto, el propósito de este artículo es presentar algunas partes de la base teórica de la tesis doctoral en curso, acerca de conceptos como orientación espacial, legibilidad, wayfinding y multisensorialidad. Se cree que el diálogo directo entre el usuario y el profesional, así como los subsidios teóricos y legales relacionados con la materia pueden contribuir a la búsqueda de soluciones de problemas de orientación espacial de los usuarios en entornos construidos.

PALABRAS CLAVE: Discapacidad visual. Orientación física y espacial. Multisensorialidad. 


\section{Revista Nacional de}

Gerenciamento de Cidades

\section{INTRODUÇÃO}

A prática projetual desenvolvida na atualidade ainda parece apontar para uma mobilização exacerbada do sentido da visão, o que coloca as pessoas com deficiência visual em situações desvantajosas que, muitas vezes, se resumem a uma dificuldade de elaborar uma rota mental adequada, a qual Ihes permita autonomia e desenvoltura na interação com o ambiente espacial, devido a inexistentes ou insuficientes marcos referenciais em um determinado espaço. Ou ainda, os projetistas tangenciam a questão adaptando minimamente os ambientes construídos. Segundo Cubukcu e Nasar (2005), estas pessoas podem deixar de visitar os espaços evitando lidar com as dificuldades impostas pelas estruturas físico-espaciais. Passini (1996) afirma que estas dificuldades expõem as pessoas a frustrações, estresse e perda de tempo, além de sentimentos de dependência e da incapacidade de realizar atividades de forma autônoma. É a partir desse ponto de vista que o artigo tenta responder à seguinte problemática: como desenvolver espaços que atendam às necessidades de pessoas com deficiência visual em sua orientação físico-espacial? Pois, segundo Castro et al (2004), a orientação é um dos mais importantes aspectos de autonomia a ser considerado, sobretudo por aqueles que têm restrições visuais.

Brandão (2011) expõe a visão de Froyen (2006 apud BRANDÃO, 2011), o qual afirma que os projetistas desconhecem a percepção espacial de pessoas com deficiência visual, o que pode explicar a dificuldade deles em buscar soluções que facilitem a sua percepção e orientação espacial. Para Froyen:

(...) o sentido tátil (texturas ao pisar, paredes, corrimãos, correntes de ar, radiação solar, etc), sons (tráfego, vozes, pássaros, vento, passos, eco, etc.), odores (tráfego, lixo, perfumes, comidas, plantas, etc.), tudo contêm uma rica, mas geralmente ignorada paleta de impulsos para uma experiência sensorial (FROYEN, 2006 apud BRANDÃO, 2011).

As pessoas com deficiência visual se apropriam ou percebem os espaços através de mecanismos e estratégias sensoriais que são diferentes daqueles 


\section{Revista Nacional de}

Gerenciamento de Cidades

empregados por pessoas videntes ${ }^{3}$. As pessoas cegas e com baixa visão, a partir dos seus esquemas mentais, do seu sistema neuro-sensório-motor, constroem esquemas de percepção que podem ser melhor aproveitados se forem levados em conta no desenvolvimento de projeto. Ao conviver e dialogar com estas pessoas, percebe-se que elas passam a prestar atenção aos mínimos, mas significativos detalhes, para possibilitar a sua percepção e orientação espacial. Assim, compreender essa especificidade perceptiva parece ser um caminho indispensável para solucionar problemas de orientação espacial e, consequentemente, promover a acessibilidade físico-espacial ${ }^{4}$.

Este artigo se justifica pela necessidade de abordar esta temática, dada a sua relevância, pois Dischinger e Bins Ely (2010) afirmam que enquanto o conhecimento relacionado à acessibilidade para pessoas com deficiências físicas é bastante significativo, as deficiências sensoriais como campo de pesquisa ainda precisam de maior aprofundamento nas soluções técnicas, sendo necessário estabelecer um diálogo com os usuários cegos e pessoas com baixa visão a fim de compreender os seus processos de percepção e orientação espacial. Além disso, ao desenvolver espaços mais acessíveis para pessoas com deficiência visual, Paula (2006) afirma que "também estará se produzindo subsídios para ampliar a qualidade arquitetônica para os não-cegos".

Diante do exposto, o presente artigo pretende apresentar alguns conceitos concernentes a esta temática, como orientação espacial, legibilidade, wayfinding e multissensorialidade. Ademais, pretende também sensibilizar os futuros profissionais envolvidos em projetos arquitetônicos, urbanísticos e de interiores sobre a importância de incluir a participação de usuários no processo desenvolvimento de projeto, assim estabelecendo um diálogo importante entre as partes. Acredita-se que ao adotar uma prática mais humana no desenvolvimento de projeto, o profissional

\footnotetext{
${ }^{3}$ Pessoas que enxergam normalmente.

${ }^{4}$ Segundo Dischinger, Bins Ely e Piardi (2012), a acessibilidade físico-espacial não é apenas a possibilidade de atingir um lugar desejado, mas também a possibilidade de compreender a função, a organização e as relações espaciais, bem como a possibilidade de participação das atividades existentes nele.
} 
Revista Nacional de

Gerenciamento de Cidades

poderá criar espaços acessíveis, onde as pessoas com deficiência visual poderão perceber os espaços de forma plena e orientar-se neles através de seus sentidos remanescentes.

\section{A DEFICIÊNCIA VISUAL}

De acordo com o censo realizado pelo IBGE em 2010, cerca de 45,6 milhões brasileiros possuem algum tipo de deficiência, o que corresponde a $23,9 \%$ da população brasileira, sendo 35,7 milhões acometidos pela cegueira ou baixa visão. Conforme demonstra a Figura 1, a deficiência visual é aquela de maior incidência, o que reforça a necessidade de dar atenção especial a esta parcela significativa da população.

Figura 1. O percentual de pessoas com deficiência no Brasil por segmento

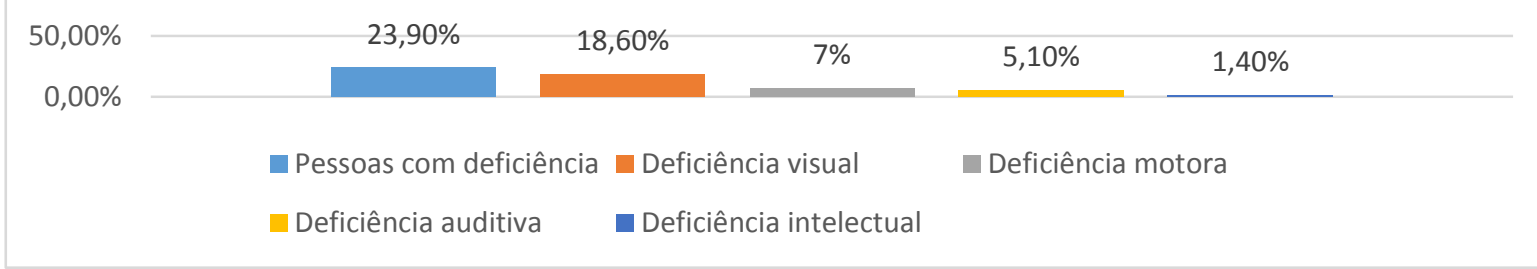

Fonte: IBGE, 2010.

A deficiência visual não compreende apenas a ausência de visão, pois há formas de enxergar diferentes entre si que se configuram como deficiência visual, englobando dois grandes grupos: a cegueira e a baixa visão. Estes grupos são delimitados por escalas oftalmológicas: acuidade visual, que possibilita enxergar de forma precisa os objetos a uma determinada distância, e campo visual, que significa a amplitude da área alcançada pela visão, isto é, abrange tudo o que pode ser visto como um todo sem movimentar os olhos.

A deficiência visual pode ser adquirida em qualquer estágio da vida - após o nascimento - ou congênita, desde o nascimento, decorrente de causas genéticas, 


\section{Revista Nacional de}

Gerenciamento de Cidades

acidentais ou ainda decorrente de doenças como diabetes, deslocamento de retina, entre outras. Uma pessoa que adquiriu a cegueira ao longo da vida possuirá memórias visuais, ou seja, consegue se lembrar de coisas que foram vistas antes de perder a visão, e então estas memórias ficam preservadas. Já a pessoa que nasceu com cegueira total não terá a capacidade de formar imagens visuais, mas em contrapartida, desenvolve estratégias para estruturar a representação mental do espaço (CONDE, 2005; CONDE, 2012; GIL, 2000).

A visão pode ser afetada de diversas formas, como a perda de nitidez, perda de visão periférica e/ou visão central, manchas no campo visual, ofuscamento, incapacidade de distinção de cores, etc. As pessoas com baixa visão podem ter dificuldades de reconhecer um rosto, de distinguir contornos de um ambiente pela ausência de visão periférica, de focar no objeto desejado ou de ler pela falta de visão central, entre outras. Enquanto que há pessoas cegas que têm alguma percepção de luz, outras não possuem qualquer resíduo visual. No entanto, utilizam os demais sistemas perceptivos (audição, orientação, háptico, sistema olfatopaladar) para a orientação e locomoção, assim como podem utilizar-se de bengala longa, um instrumento geralmente utilizado por indivíduos cegos e com baixa visão para orientação e mobilidade. Santos et al (2007) e Gil (2000) acrescentam que as pessoas com baixa visão, além de acuidade e/ou campo visual comprometidos, apresentam dificuldades de enxergar com clareza, adaptação à luz, ao escuro e à percepção de cores, são sensíveis aos contrastes, mas são potencialmente capazes de realizar tarefas utilizando a visão residual, usando recursos ópticos (óculos, lupas, etc.).

\subsection{Os sentidos da percepção}

As pessoas utilizam estratégias perceptivas para explorar e identificar espaços, adquirindo informações espaciais por meio de toque e da audição. Segundo Ormelezi (2000), essas informações são adquiridas de forma sequencial, 


\section{Revista Nacional de}

Gerenciamento de Cidades

sendo necessária uma interação contínua. Para Lawson (1994), a percepção é um processo complexo através do qual os indivíduos selecionam, organizam e interpretam estímulos sensoriais. Lynch (2006) afirma que quase todos os sentidos estão envolvidos no processo de percepção, que não é íntegra e ocorre de forma parcial e fragmentária. Gibson (1966) explica que existem dois significados do verbo sentir, que pode significar tanto "detectar algo" quanto "ter uma sensação". $\mathrm{Na}$ primeira definição, os sentidos atuam como sistemas perceptivos, já a segunda definição tem uma carga mais subjetiva. Reid (1785 apud GIBSON, 1966) traz uma concepção mais clara a respeito dos sentidos:

Os sentidos externos têm dois propósitos: para nos fazer sentir e nos fazer perceber. Eles nos fornecem uma variedade de sensações, algumas agradáveis, outras dolorosas, e outros indiferentes; ao mesmo tempo, eles nos dão uma concepção e uma crença invencível da existência de objetos externos. [...] Essa concepção e a crença que a natureza produz por meio dos sentidos, chamamos de percepção. A percepção e a sensação são produzidas ao mesmo tempo (REID, 1785 apud GIBSON, 1966).

Gehl (2014) divide os sentidos em dois grupos: o primeiro se refere aos sentidos da distância, onde estão incluídos a visão, a audição e o olfato, pois "nossos olhos, ouvidos e nariz voltam-se para frente, para nos ajudar a perceber perigos e oportunidades na rota adiante" (GEHLS, 2014). Outro grupo se refere aos sentidos de proximidade, que são o tato e o paladar, que abrangem uma esfera mais íntima. Estes sentidos classificam-se da seguinte maneira:

\section{Grupo 1: Sentidos da distância}

- Visão: De acordo com Fúnez (2013), a visão implica em discernir, priorizar e catalogar. É a partir da seleção que ocorre a interpretação.

- Audição: Permite localizar fontes sonoras, além de julgar distância. Um som cria uma sensação de interioridade enquanto que o sentido da visão nos implica com o exterior (FÚNEZ, 2013; PALLASMAA, 2011). Ouvir articula a compreensão do espaço, que exerce uma influência sobre a imaginação, pois ao distinguir os sons, isto permite imaginar um espaço quando não podemos vê-lo (CASTILLO, 2009). 
Revista Nacional de

Gerenciamento de Cidades

- Olfato: Ajuda identificar as funções dos ambientes, por exemplo, sentir cheiro de pães sendo produzidos indicando que existe uma padaria. É assim que cada cidade possui seus próprios odores e sabores (FÚNEZ, 2013; PALLASMAA, 2011). Para Alckerman (1997) e Castillo (2009), não existe nada mais memorável que o odor, pois o olfato evoca mais lembranças que a visão e a audição.

\section{Grupo 2: Sentidos da proximidade}

- Tato: É o reconhecimento do espaço e do nosso entorno que se desenvolve por meio de toque, em objetos ou pessoas. Reconhece texturas, pesos, densidades e temperatura de objetos, assim como também interpreta. Além da visão, o tato é a única modalidade que permite a um indivíduo entender as qualidades espaciais de um objeto como forma e tamanho. No entanto, toque difere da visão à medida que exige o contato direto e a continuidade dos movimentos. Pode ser considerada uma modalidade mais lenta, visto que a sua extensão é menor do que a visão (FÚNEZ, 2013; SCHINAZI, 2008).

- Paladar: o olfato e o paladar são sentidos interrelacionados, mas o paladar não possui a extensão espacial, pois se refere à dimensão social, em que os seres humanos comem a sós ou com a família, amigos e colegas. Nesse sentido, o paladar tem a função de provar ou degustar (ALCKERMAN, 1997; CASTILLO, 2009).

\section{A ORIENTAÇÃO ESPACIAL DAS PESSOAS COM DEFICIÊNCIA VISUAL}

As pessoas cegas geralmente recorrem às informações sonoras, cinestésicas, táteis, térmicas e olfativas através dos sentidos remanescentes em um determinado ambiente, seja de natureza ou construído. As pessoas com baixa visão, além de recorrer a esses tipos de informações para percepção e orientação 


\section{Revista Nacional de}

Gerenciamento de Cidades

espacial, também buscam aproveitar o máximo de resíduo visual que possuem. Estas pessoas ainda utilizam recursos de tecnologia assistiva que auxiliam nos processos de orientação espacial e de mobilidade, como a bengala longa, cão-guia, entre outros.

Primeiramente, convém elucidar as conceituações de orientação espacial que variam de autores, como Felippe e Felippe (1997) que definem a orientação espacial como sendo a habilidade de um indivíduo de perceber o ambiente, estabelecendo relações corporais, espaciais e temporais com o mesmo. Orientar-se não é apenas estabelecer posição no espaço, como também, para Dischinger (2000), vai além da mobilidade independente, onde existe a noção de saber onde se situa, como também a capacidade de identificar lugares, possíveis rotas em direção a objetivos desejados e poder tomar decisões com autonomia. Bins Ely e Dischinger (2010) consideram como uma ação intencional que envolve uma compreensão básica de situações espaço-temporais e de relações espaciais em contextos físicos. Bins Ely (2004) acrescenta que a orientação não apenas é influenciada pelas experiências vividas por cada indivíduo como também depende da capacidade do espaço em oferecer ao indivíduo informação necessária.

Particularmente para as pessoas com deficiência visual, orientar-se em espaços é uma tarefa que requer um conjunto de habilidades sensório-motorcognitivas, como a percepção, codificação, aprendizagem e recall de informação espacial. Tal tarefa pode ser particularmente estressante, especialmente quando a maioria das informações requeridas para o mapeamento mental é coletada preferencialmente pelo canal visual (ESPINOSA et al, 1998).

Dogu e Erkip (2000) afirmam que existem dois fatores que afetam o processo de orientação espacial: o layout do ambiente e a qualidade das informações existentes neste ambiente. De acordo com Dischinger (2000), a capacidade de orientar-se depende de duas esferas conectadas entre o mundo e o indivíduo (Quadro 1). 


\section{Quadro 1. As esferas da orientação espacial}

\begin{tabular}{|c|c|c|c|}
\hline \multicolumn{2}{|c|}{$\begin{array}{c}\text { Esfera do indivíduo } \\
\text { Referências pessoais } \\
\end{array}$} & \multicolumn{2}{|c|}{$\begin{array}{l}\text { Esfera do mundo } \\
\text { Estrutura de informação ambiental }\end{array}$} \\
\hline $\begin{array}{l}\text { Condições da } \\
\text { percepção }\end{array}$ & $\begin{array}{l}\text { O que e como é percebido por } \\
\text { cada um dos sistemas } \\
\text { perceptivos; prever } \\
\text { informações acerca da } \\
\text { organização espacial do } \\
\text { ambiente e movimentos no } \\
\text { espaço; }\end{array}$ & $\begin{array}{l}\text { A configuração } \\
\text { espacial dos } \\
\text { elementos } \\
\text { dinâmicos e } \\
\text { permanentes }\end{array}$ & $\begin{array}{l}\text { Organizada de acordo com as } \\
\text { leis naturais e valores culturais } \\
\text { são potenciais fontes de } \\
\text { informação com atributos } \\
\text { específicos; }\end{array}$ \\
\hline $\begin{array}{l}\text { Conhecimento } \\
\text { espacial }\end{array}$ & $\begin{array}{l}\text { Baseado na experiência e no } \\
\text { aprendizado cultural; permite } \\
\text { a interpretação, identificação, } \\
\text { e compreensão das } \\
\text { informações ambientais com a } \\
\text { finalidade de agir; }\end{array}$ & \multirow[t]{2}{*}{$\begin{array}{l}\text { Relações } \\
\text { espaciais }\end{array}$} & \multirow[t]{2}{*}{$\begin{array}{l}\text { Ações humanas organizadas } \\
\text { de acordo com os significados } \\
\text { culturais, normas e regras } \\
\text { sociais. }\end{array}$} \\
\hline $\begin{array}{l}\text { Ações } \\
\text { intencionais }\end{array}$ & $\begin{array}{l}\text { Intenções pessoais, } \\
\text { exploração e atos sociais. }\end{array}$ & & \\
\hline
\end{tabular}

Fonte: Dischinger, 2000 (tradução livre).

Passini e Proulx (1988) realizaram uma análise sobre dois grupos, um com deficiência visual e outro com visão normal. Nesta análise, os referidos autores descobriram que os participantes com deficiência visual, em relação aos participantes videntes, tendem a preparar sua rota de forma mais detalhada, onde foram tomadas muitas decisões que dependiam de mais informações ambientais. Segundo O'Conneil (2010), grande parte dos casos de deficiência visual são distintos/individualizados, visto que existem aqueles com algum resíduo visual cuja experiência difere daqueles que não possuem alguma percepção visual; e existem, também, aqueles que têm a percepção de luz, podendo identificar a fonte e perceber mudanças na luz, o que pode ser relevante nos processos de percepção e de orientação espacial. E quanto às pessoas que perderam tardiamente a visão, estas apresentam capacidades diferentes daquelas que nasceram com cegueira. Portanto, essa diversidade que existe na deficiência visual se torna um desafio para 0 desenvolvimento de projetos que contemplem as necessidades de todo o espectro (O'CONNEIL, 2010). 


\section{Revista Nacional de}

Gerenciamento de Cidades

Quando se trata de perceber e entender um determinado ambiente com clareza, o conceito de legibilidade é de extrema importância para os estudos de orientação espacial sob ponto de vista de Lynch (2006):

[...] a imagem clara permite ao indivíduo deslocar-se facilmente e depressa [...] Mas o meio ambiente organizado pode fazer muito mais do que isto; pode servir como estrutura envolvente de referência, um organizador de atividade, crença ou conhecimento. [...] um meio ambiente característico e legível não oferece apenas segurança, mas também intensifica a profundidade e a intensidade da experiência humana (LYNCH, 2006).

Para Dogu e Erkip (2000), um lugar que facilita a compreensão do espaço apresenta boas condições de legibilidade, ou seja, um lugar que apresenta facilidade de leitura contribui para a construção dos mapas mentais. Do contrário, se o espaço é confuso e provoca dificuldades de orientação, isto significa que o espaço possui um baixo fator de legibilidade.

Outro conceito bastante relevante para a orientação espacial em ambientes construídos é o wayfinding, também conhecido como "movimento orientado" (BERNARDI, 2007). No entanto, convém esclarecer a distinção entre esse conceito e orientação espacial, que muitas vezes são utilizados como sinônimos. Para Passini (1984), wayfinding se refere à capacidade do indivíduo em determinar sua localização no ambiente, de se situar no mesmo e poder chegar ao destino desejado. É um processo de resolução de problemas espaciais que abrange a tomada e execução de decisões, como também o processo de informações. Já a orientação espacial, conforme Mohammed (2010), consiste na capacidade do indivíduo em compreender o espaço à sua volta e obter sua localização. $O$ autor ainda observou que wayfinding é tratado também como sinônimo de mobilidade, porém ambos são parcialmente diferentes. Enquanto mobilidade baseia-se apenas na habilidade física, wayfinding é uma habilidade tanto cognitiva quanto comportamental onde o indivíduo objetiva alcançar o destino. É um processo sequencial, de fundamental importância para a orientação espacial dos usuários, 


\section{Revista Nacional de}

Gerenciamento de Cidades

pois quando bem sucedido, traz sentimentos positivos como satisfação e segurança, além de reduzir o tempo gasto (PASSINI, 1984; MOHAMMED, 2010).

É importante notar que, de acordo com Cubukcu e Nasar (2005), layouts complexos tendem a dificultar o processo de wayfinding. Além disso, um espaço monótono, onde não existe alguma diferenciação e a falta de pontos de referência também são considerados como fatores que dificultam wayfinding (Passini et al, 2000), especialmente para pessoas com baixa visão. Em vista disso, Bentley et al (1985) dizem que é de fundamental importância que o layout seja legível de modo que as pessoas sejam capazes de formar imagens claras e precisas do ambiente. Belir e Onder (2013) argumentam que o layout deve ser planejado levando-se em consideração a implementação de marcos sensório-estruturais. Dessa forma, alcançar-se-á boa legibilidade espacial.

Ainda segundo Lynch (2006), a sinalização, a configuração arquitetônica, o planejamento do layout são principais fatores de legibilidade espacial que facilitam a orientação espacial de um indivíduo. Portanto, entende-se que a legibilidade deve ser levada em consideração ao se projetar ambientes construídos, uma vez que afeta não apenas o processo de orientação espacial como também os aspectos cognitivos, perceptivos e emocionais dos usuários. Pois, segundo Passini et al (2000), quando um local não contribui para a orientação espacial, a autonomia e qualidade de vida dos indivíduos são comprometidas.

Para Dischinger (2000), saber reconhecer a identidade e função dos espaços através dos elementos que os compõem não é o bastante, pois é preciso, para o indivíduo, estar ciente do lugar que ocupa identificando o entorno por meio de referências temporal-espaciais. Bins Ely e Dischinger (2010) afirmam que projetos de orientação espacial para pessoas com deficiência visual exigem uma análise detalhada do espaço, identificando informações potenciais que permitam as pessoas em questão a localizar e identificar atividades, percursos, referenciais, bem como compreender as relações espaciais. 
Revista Nacional de

Gerenciamento de Cidades

\section{MULTISSENSORIALIDADE E A HEGEMONIA DA VISÃO}

De acordo com Herssens e Heylighen (2011), a arquitetura é vivenciada com todos os sentidos, mas o sentido da visão tende a receber maior atenção de projetistas. Vermeersch et al (2009) demonstraram em sua pesquisa que os arquitetos geralmente tendem a centralizar a sua própria experiência espacial sem considerar as experiências de outros. Para Fúnez (2013), a arquitetura se esqueceu de seu principal elemento: o ser humano, pois a arquitetura atual foi e é concebida para agradar aos olhos, considerados como órgãos prediletos em detrimento de outros sentidos, como o tato, a audição, o olfato e o paladar. Assim, termina por desconsiderar o ser humano como um ser perceptivo em todos os sentidos, sem que haja possibilidades de perceber o espaço através dos sentidos comumente ignorados pelos profissionais, como arquitetos, urbanistas e designers de interiores. De acordo com Herssens e Heylighen (2007), a predileção pela visão é inerente ao cérebro humano que é alimentado pela cultura ocidental. Como resultado disso, estamos diante de uma arquitetura deficiente. Restrepo (1998) considera a nossa cultura como sendo audiovisual, pois “(...) frente a uma percepção mediada pelo tato, gosto ou olfato, o Ocidente preferiu o conhecimento dos exteroceptores, ou receptores à distância, como são a visão e o ouvido". Em vista disso, Sousa (2004) sugere que as percepções tátil e visual, embora sejam distintas, não devem ser tratadas como antagônicas.

Esta hegemonia da visão coloca uma grande parcela da população em desvantagem, sobretudo as pessoas com deficiência visual que geralmente estão em situações de dependência de terceiros ao confrontar o mundo repleto de referências visuais. Para Castillo (2009), diante do império da visão no campo de arquitetura e de urbanismo, faz-se necessário integrar o conceito de arquitetura multissensorial a fim de que todos os indivíduos, com as suas capacidades e limitações diferentes, possam desfrutar dos espaços democraticamente. 


\section{Revista Nacional de}

Se arquitetos e projetistas criam ambientes "visuais" sem levar em consideração o usuário e a multissensorialidade, essa criação resulta em "espaços distorcidos" por não estarem compatíveis com as necessidades de toda a diversidade dos usuários. Portanto, faz-se necessário reconsiderar a maneira como a arquitetura é concebida e ensinada, criando projetos que provoquem não apenas a visão, como também os demais sentidos, pois o espaço não deve ser apenas funcional, deve transcender a um mero espaço físico em que se pode vivenciar além da percepção visual, assim criando o sentimento de pertencimento ao lugar (HERSSENS \& HEYLIGHEN, 2007; PALLASMAA, 2011).

Castillo (2009), então, propõe uma arquitetura centrada na pessoa sem perder a funcionalidade do espaço. Fúnez (2013) recomenda desenvolver um projeto arquitetônico no qual a ausência de visão seja a chave, incorporando sensações que nos levam a outros sentidos.

Vermeersch et al (2013) acreditam que o diálogo entre os profissionais de projeto e as pessoas com deficiência visual pode contribuir para uma abordagem de arquitetura multissensorial. Faria e Elali (2012) defendem um projeto participativo durante a sua fase de desenvolvimento, visando estreitar o contato entre projetistas e usuários, pois "no caso da ausência total ou parcial de visão, boas soluções exigem, além de conhecimento teórico, contato direto com usuários" (FARIA \& ELALI, 2012). Bernardi (2007) ainda complementa sobre esta questão:

[...] [o usuário] pode indicar quais estímulos ambientais devem prevalecer no projeto para que as suas sensações auxiliem a sua orientação e mobilidade no ambiente, mas é competência do projetista identificar e gerenciar as respostas realmente significativas para transformá-las em soluções arquitetônicas de qualidade (BERNARDI, 2007).

\section{CONCLUSÃO}

Diante do exposto, entende-se que levar em consideração os conceitos apresentados neste artigo não apenas auxiliam os processos de percepção e de 


\section{Revista Nacional de}

Gerenciamento de Cidades

orientação espacial de pessoas com deficiência visual, como também complementa as necessidades de inúmeros outros usuários com diversas aptidões. Portanto, torna-se essencial aproximar o usuário e o projetista durante o planejamento de espaços para que o projetista consiga desenvolver um projeto mais próximo possível de um ambiente que o usuário idealiza.

O conhecimento das necessidades e dos anseios dos usuários com deficiência visual pode ajudar os profissionais a solucionar problemas de orientação e mobilidade, proporcionando condições ideais de acessibilidade.

A esse respeito, Sousa (2004) assevera:

É tempo de darmos alguma atenção a essa realidade específica, que configura o modo como os indivíduos cegos situam-se no mundo: as estratégias das quais lançam mão para construir sua própria visão da realidade. É tempo de darmos voz à nossa própria experiência de como vivenciamos o mundo enquanto habitantes desse universo tátil em que corpo, aparelho neuro-sensório-motor, mente e ambiente constroem uma visão particular do real (SOUSA, 2004).

Parece, pois, que um primeiro passo para a efetivação de projetos que possam contemplar essa diversidade perceptiva exige o conhecimento dessa variedade de questões. Um segundo passo resultará do trabalho do diálogo entre os profissionais e os usuários e da experimentação de estratégias que possibilitem a valorização dessa multissensorialidade, com estratégias de legibilidade espacial.

\section{REFERÊNCIAS}

BELIR, O; ONDER, D. E. Accessibility in public spaces: spatial legibility for visually impaired people. $9^{\text {th }}$ International Space Syntax Symposium, Seoul, 2013.

BENTLEY, I.; ALCOCK, A.; MURRAIN, P.; McGLYNN, S.; SMITH, G. Responsive environments: a manual for designers. Ed. Architectural Press. Oxford. 1985.

BERNARDI, N. A aplicação do conceito do Desenho Universal no ensino de arquitetura: o uso de mapa tátil como leitura de projeto. Tese (Doutorado). Universidade Estadual de Campinas, Faculdade de Engenharia Civil, Arquitetura e Urbanismo. Campinas, SP: 2007. 


\section{Revista Nacional de}

Gerenciamento de Cidades

BINS ELY, V. H. M. Orientar-se no espaço: condição indispensável para a acessibilidade. In: Seminário Nacional Acessibilidade Cotidiano, I, 2004. Rio de Janeiro. Anais... Rio de Janeiro: UFRJ, 2004.

BINS ELY, V. H. M.; DISCHINGER, M. Deficiência visual, processos de percepção e orientação. In: LOPES et al. (Orgs.). Desenho Universal: caminhos da acessibilidade no Brasil. São Paulo: Ed. Annablume, 2010.

BRANDÃO, Milena de M. Acessibilidade espacial para pessoas com deficiência visual: discussão e contribuições para NBR 9050/2004. 2011. Dissertação (Mestrado em Arquitetura e Urbanismo) - Universidade Federal de Santa Catarina (UFSC). Florianópolis, SC.

CASTILLO, Y. Criterios de diseño polisensorial aplicables en la arquitectura habitacional en la ciudad de Loja. Tese de Doutorado. Universidade de Loja Ecuador. 2009.

CASTRO, E. M.; PAULA, A. I.; TAVARES, C. P.; MORAES, R. Orientação espacial em adultos com deficiência visual: efeitos de um treinamento de navegação. Psicologia: Reflexão e Crítica. Vol. 17, no 2. 2004. 199-210p.

CONDE, A. J. M. Definindo a cegueira e a deficiência visual. 2005. Disponível em: < http://www.laboratoriorigor.com.br/ler_noticia,4.html >. Acesso em 30 de abril de 2013.

CONDE, A. J. M. Deficiência visual: a cegueira e a baixa visão. 2012. Disponível em: $<$ http://www.bengalalegal.com/cegueira-e-baixa-visao > Acesso em 30 de abril de 2013.

CUBUKCU, E.; NASAR, J. Relation of Physical Form to Spatial Knowledge in Largescale Virtual Environments. Environment and Behavior. May 2005. Vol. 37, oㅜ 3. 397-417p. Disponível em: $<$ http://eab.sagepub.com/content/37/3/397.short> Acesso em 19 de outubro de 2014.

DISCHINGER, M. Designing for all senses: Acessible spaces for visually impaired citizens. 2000. Tese (Doutorado em Filosofia) - Departament of Space and Process School of Architecture, Chalmers University of Technology. Göteberg, Suécia.

DISCHINGER, M.; BINS ELY, V.; PIARDI, S. Promovendo Acessibilidade espacial nos edifícios públicos: Programa de Acessibilidade às Pessoas com Deficiência ou Mobilidade Reduzida nas Edificações de Uso Público. Ministério Público do Estado de Santa Catarina. Florianópolis, 2012.

DOGU, U.; ERKIP, F. Spatial factors affecting wayfinding and orientation: a case study in a Shopping Mall. Environment and Behavior. Vol. 32, № 6. 731-755p. 2000.

ESPINOSA, M.; UNGAR, S.; OCHAÍTA, E.; BLADES, M. Comparing methods for introducing blind and visually impaired people to unifamiliar urban environments. Journal of Environmental Psychology 18, p. 277-287. Academic Press. 1998. 


\section{Revista Nacional de}

Gerenciamento de Cidades

FARIA, A. T.; ELALI, G. A. Promovendo a inclusão: uma experiência de participação de pessoa com deficiência visual no desenvolvimento de um projeto arquitetônico. Revista Ergonômica, v. 7, n. 2, 2012.

FELIPPE, J.; FELIPPE, V. Orientação e Mobilidade. São Paulo: Laramara - Associação Brasileira de Assistência ao Deficiente Visual, 1997. 179p.

FÚNEZ, A. S. Busqueda de los sentidos a través de la arquitectura: un proceso de investigación. Arte y Movimiento. Vol. 8. Junio 2013.

GIBSON, J. The senses considered as perceptual systems. 1를 Edição. Editora: Praeger. 1966. 335p.

GIL, M. Deficiência visual. Cadernos da TV Escola I. Brasília: MEC - Secretaria de Educação à Distância, 2000. 80p.

HERSSENS, J.; HEYLIGHEN, A. Haptic architecture becomes architectural hap. Nordic Ergonomic Society. Annual Congress of the Nordic Ergonomic Society (NES) edition: 39. Article 34. Lisekil, Sweden. 1 a 3 de Outubro de 2007.

HERSSENS, J.; HEYLIGHEN, A. Haptic design research: a blind sense of place. Em: The Place of Research. The Research of Place. Proceedings of the 2010 International Conference on Architectural Research. 2011.

HERSSENS, J.; HEYLIGHEN, A. Designerly Ways of not knowing: what designers can learn about space from people who are blind. Journal of Urban Design, v. 19, n. 3, p. 317-332. 2014.

IBGE. Censo demográfico 2010. Instituto Brasileiro de Geografia e Estatística, 2010.

LAHAV, O.; MIODUSER, D. Blind persons' acquisition of spatial cognitive mapping and orientation skills supported by virtual environment. International Journal on Disability and Human Development. Vol. 4, no 3. 2004. 231-238p.

LONG, R. G.; GIUDICE, N. A. Establishing and maintining orientation for mobility. In: B. B. Blasch, W. R. Wiener \& R. W. Welsh (Eds.), Foundations of Orientation and Mobility ( $3^{\text {rd }}$ Edition, Vol. 1: History and Theory). New York: American Foundation for the Blind. 2010. 45-62p.

LOPES, M. E; BURJATO, A. L. P. Ergonomia e Acessibilidade. In: LOPES et al. (Orgs.). Desenho Universal: caminhos da acessibilidade no Brasil. São Paulo: Ed. Annablume, 2010.

LYNCH, K. A imagem da cidade. São Paulo: Martins Fontes, 2006.

MOHAMMED, A. A. Spatial conditions for sustainable communities: the case of informal settlements in GCR. Research Proposal (Faculty of Engineering - Departament of Urban Planning) Ain Shams University. Cairo, Egypt. 2010. Disponível em: <http://www.cpasegypt.com/pdf/Abd_ElBaser/M.SC/002.pdf>. Acesso em 19 de novembro de 2014. 


\section{Revista Nacional de}

Gerenciamento de Cidades

O'CONNEL, E. K. Senses of place. Thesis (Master of Architecture). School of Architecture and Interior Design - College of Design, Architecture, Art and Planning. 2010.

Ormelezi, E. M. (2000). Os caminhos da aquisição do conhecimento e a cegueira: do universo do corpo ao universo simbólico. Dissertação de mestrado, Faculdade de Educação, Universidade de São Paulo, São Paulo.

PALLASMAA, J. Os olhos da pele: a arquitetura e os sentidos. Editora: Bookman. 2011.

PASSINI, R.; PROULX, G. Wayfinding withou vision: an experimente with congenitally totally blind people. Environment and Behavior. Vol. 20, no 2. 1988. 227-252p.

PASSINI, R.; PIGOT, H.; RAINVILLE, C.; TÉTREAULT, M. Wayfinding in a nursing home for advanced dementia of the Alzheimer's type. Environment and Behavior. September 2000. Vol. 32, ำ 5. 684-710.

PASSINI, R. Spatial representations, a wayfinding perspective. Journal of Environmental Psychology. Vol. 4. 153-164p. 1984.

PASSINI, R. Wayfinding design: logic, application and some thoughts on universality. Design Studies 17. Elsevier Science Ltda. 1996.

PAULA, K. C. L.; DUARTE, C. R. Vivências espaciais: a construção do lugar pelos cegos. Cadernos do PROARQ. Rio de Janeiro: Universidade Federal do Rio de Janeiro, Faculdade de Arquitetura e Urbanismo, Programa de Pós-Graduação em Arquitetura - vol. 10, 2006.

PAULA, N.; DENCKER, A. Uma refeição inesquecível: contribuição para a interpretação sobre o consumo em restaurantes, sob a perspectiva sociológica. $30^{\circ}$ Encontro da ANPAD. Salvador, Bahia. 23 a 27 de setembro de 2006.

RESTREPO, L. C. O direito à ternura. Petrópolis: Vozes, 1998.

SANTOS, L.; PASSOS, J.; REZENDE, A. Os efeitos da Aprendizagem Psicomotora no Controle das Atividades de Locomoção sobre Obstáculos em Crianças com Deficiência da Visão. Rev. Bras. Ed. Esp 2007; 13: 365-380.

SOUSA, J. Aspectos comunicativos da percepção tátil: a escrita em relevo como mecanismo semiótico da cultura. Tese (Doutorado em Comunicação e Semiótica). Pontifícia Universidade Católica de São Paulo - PUC/SP. 2004.

VERMEERSCH, P.; STRICKFALDEN, M.; HERSSENS, J.; HEYLIGHEN, A. Architects and visually impaired people: analyzing two ways of talking. Em: DS 58-1: Proceedings of ICED 09, the $17^{\text {th }}$ International Conference on Engineering Design, vol. 1, Design Processes, Palo Alto, CA, EUA. 2009. 
